Pontifícia Universidade Católica

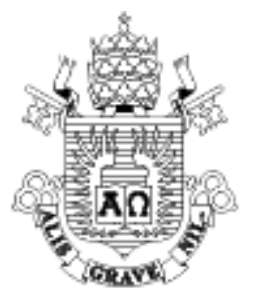

Cristina Maria Lara Guimarães

NOVOS MÉTODOS E BASES DE UMA EXPRESSÃO COMPETENTE NA FORMAÇÃO MÉDICA

MONOGRAFIA

ESCOLA MÉDICA DE PÓS-GRADUAÇÃO

Curso de Pós-Graduação Lato sensu

Especialização em Formação Docente em Medicina e

Ciências da Saúde: novas metodologias

Rio de Janeiro

2015 


\title{
NOVOS MÉTODOS E BASES DE UMA EXPRESSÃO COMPETENTE NA FORMAÇÃO MÉDICA
}

\author{
Monografia apresentada ao Centro \\ de Ciências Biológicas e da Saúde \\ da PUC-Rio como requisito parcial \\ para conclusão do curso de \\ Especialização em Formação \\ Docente em Medicina e Ciências da \\ Saúde: novas metodologias
}

Orientador: Jorge Biolchini

Rio de Janeiro

2015

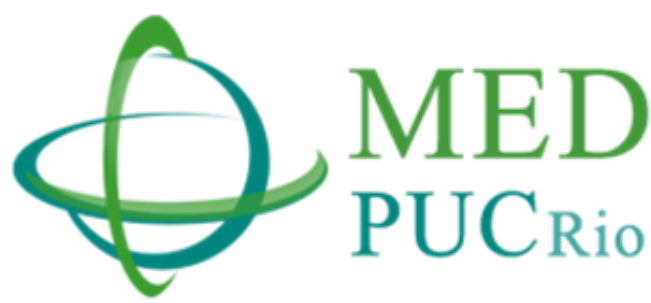


Dedico este trabalho aos meus pais Maria e José Lara (in memoriam) E ao meu amado marido, que me deu todo apoio e incentivo carinhoso 
Agradecimentos

Agradeço a amiga Denise Gusmão por me ajudar em todo o processo de construção deste trabalho com seu carinho e conhecimento.

Agradeço ao Professor e amigo Jorge Biolchini pela oportunidade de acrescentar a minha vida, pessoas e conhecimentos que ficarão para sempre.

Agradeço a minha turma Alfa todo carinho e acolhimento que sempre estiveram prontos a ajudar e trocar. Obrigada turma querida.

Agradeço a coordenação da MED PUC Rio, em especial a Solange que sempre esteve presente nas nossas dificuldades. 
Ao começar a praticar, seja tenaz como um cervo, que, preso num cercado, tenta escapar. No meio, seja como um lavrador que, durante a colheita, não espera coisa alguma. No fim, seja como um pastor que trouxe o rebanho para casa. Palavra sagrada, de Patrul Rinpoche 


\section{RESUMO}

Este trabalho tem como propósito elaborar um modelo pedagógico sobre os temas "relação materno-infantil" e "tristeza" como disciplina clínica para a graduação médica, utilizando o método de aprendizagem ativa de ensinoaprendizagem. Serviram de referencial para a elaboração da proposta pedagógica os documentos "Proposta pedagógica para Graduação Médica Contemporânea"-modelo PUC Rio, publicado em 2011 e as "Diretrizes Curriculares Nacionais para a Graduação de Medicina", publicadas em 2014. Para a elaboração do conteúdo técnico, utilizo fundamentalmente as recomendações da Organização Mundial da Saúde, em abril de 2013 e que tem como principal desafio a elaboração de novos paradigmas na relação médico-paciente assim como no processo de definição diagnóstica e terapêutica. Destaco ainda a importância das competências ética e comunicadora para uma formação médica onde a dimensão humana e técnica não estejam dissociadas. Entendendo que mudanças e transições implicam em trabalho de longo prazo e, sobretudo com jovens iniciantes no caminho da medicina, este trabalho pretende dar uma contribuição no processo de humanização da nova medicina em curso.

Palavras-chave: Metodologia Ativa, Graduação médica, competência técnica, ética e comunicadora, paradigma, humanização, transição. 


\section{ABSTRACT}

The purpose of this research is to elaborate a pedagogic model on "maternalinfant relationship" and "sadness" as a clinical subject for medical graduation courses, employing the active-learning method in the teaching-learning process. The elaboration of this pedagogical proposal was based on the papers "Proposta pedagógica para Graduação Médica Contemporânea"-modelo, PUC University - Rio de Janeiro, published in 2011, and "Diretrizes Curriculares Nacionais para a Graduação de Medicina", published in 2014. As a main reference for the technical contents, the recommendations of the World Health Organization (2013) are followed, where the key chalenges covered are paradigm shifts in the physician-patient relationship, and in the diagnostic definition and therapeutic processes. In addition, the research stresses the importance of the competence both in ethics and communication for a medical training where the human and technical dimensions are not decoupled. It is understood that changes and transitions are long term processes, mainly when it comes to young beginners aiming for a medical career path. The objective of this research is to make a contribution to the humanization process of the medicine.

Key words: Active Methodology, Medical Graduation, technical competence, ethics and communication, paradigms, humanization, transition. 


\section{SUMÁRIO}

1. Introdução 9

2. Ciclo1: Atenção Materno-infantil 16

2.1. Vivência de Plenitude Mental - mediação cognitiva 17

2.2. Reflexões sobre o vivido - Caminhar para Si 20

2.3. Leitura e análise teórica - metodológica: estudo do conteúdo 22

2.4. Produção de sentido- do caminhar para si ao revelar-se ao outro 23

2.5. Avaliação 24

3. Tristeza - saúde mental e transtornos afetivos: Ciclo 2

4. Considerações Finais 33

5. Referências Bibliográficas 34 



\section{Introdução}

Estamos impregnados de futuro em nosso trabalho, seja porque o objetivo dele tem que ser a edificação de uma nova realidade, seja porque nossos alunos estão imbuídos de futuro: eles são, também, futuro. Nesse sentido, o estar impregnado tem uma significação como se a palavra fosse "emprenhado", portanto, grávido. Mario Sergio Cortella

Um dos desafios da educação contemporânea está em propiciar uma formação profissional que não dissocie a teoria da prática e também que estimule a construção da autonomia individual em interação com a dimensão coletiva. Assim, para que tenhamos no futuro, cada vez mais profissionais capazes de agir no mundo com responsabilidade social, é preciso que a formação profissional vá além da capacitação técnica e integre ética e compromisso com a cidadania.

Historicamente, a formação dos profissionais de medicina tem se baseado no uso de metodologias tradicionais influenciadas pelo mecanicismo cartesiano, fragmentado e reducionista, onde "separou-se o corpo da mente, a razão do sentimento, a ciência da ética, compartimentalizando-se, consequentemente, o conhecimento em campos altamente especializados, em busca da eficiência técnica" (Mitre et al, 2008, p.2134).

Segundo a Organização Mundial de Saúde (OMS), a saúde é o "bem estar biológico, psicológico, social e espiritual". Esta concepção, no entanto, não está em sintonia com o modelo tradicional de paradigma curricular, calcado no tecnicismo. Daí a importância e por que não dizer, a urgência, em se rediscutir os processos de ensinoaprendizagem necessários à formação profissional na área da saúde.

Mitre et al (2008) no artigo "Metodologias ativas de ensino-aprendizagem na formação profissional em saúde: debates atuais", chama a atenção para o sentido etimológico de método :

A acepção originária de método diz respeito ao caminho a ser seguido - do grego meta $=$ atrás, em seguida, através e hodós $=$ caminho -, referindo- se, por conseguinte, aos passos que deverão ser dados para se atingir um lugar ou um fim (p.2134). 
Entendendo método e metodologia como sinônimos, os autores apontam para a necessária busca de métodos inovadores que

admitam uma prática pedagógica ética, crítica, reflexiva e transformadora, ultrapassando os limites do treinamento puramente técnico, para efetivamente alcançar a formação do homem como um ser histórico, inscrito na dialética da açãoreflexão-ação(Mitre et al, 2008, p.2134).

O artigo intitulado "Conceito e Avaliação de Habilidades e Competência na Educação Médica: Percepções Atuais dos Especialistas” de Aguiar e Ribeiro (2010) traz uma importante contribuição para o debate em torno da mudança de paradigma na formação de médicos.

A melhor articulação entre teoria e prática na formação depende da construção coletiva de um saber sobre o que constitui $o$ conhecimento profissional e de como os profissionais aprendem e desenvolvem sua expertise. Implica estabelecer relações entre a produção de vários tipos de conhecimento, seu uso no contexto profissional e a educação permanente, uma tríade articulada tanto no contexto acadêmico quanto no profissional (p. 372).

Mensurando a importância desse resgate na direção do ser-saber-fazer, a aprendizagem ativa traz a possibilidade de um novo olhar na formação do indivíduo como futuro médico, humanizado em si e para o outro, desenvolvendo as bases para as competências a serem exercidas. Segundo Aguiar e Ribeiro (2010)

o conceito de competência tem sido apropriado de modo fértil na discussão sobre mudanças na formação em saúde. Ao recolocar a prática profissional no foco, ajuda a pressionar as escolas a repensar seus currículos e processos avaliativos, reorientando o planejamento educacional a partir do perfil desejável para seus egressos

A competência é a coordenação de um conjunto de conhecimentos, habilidades e atitudes (C.H.A.)

Usualmente, abordam-se conhecimentos, habilidades e atitudes como entidades diferentes e separadas, reduzindo $o$ conhecimento apenas à sua dimensão teórica, proposicional. 
Separam-se teoria e prática, conhecimento sistematizado e pessoal, pensamento intuitivo e analítico. Incluir a dimensão do significado atribuído pelo sujeito implica admitir que o conhecimento não pode ser caracterizado de forma independente de como foi aprendido e de como é usado, ou seja, o contexto da aquisição e o de seu uso são fundamentais para revelar a natureza do conhecimento (AGUIAR E RIBEIRO, 2010, p.377).

Na primeira aula do curso de "Formação Docente em Medicina e Ciências da Saúde", recordo-me que falei sobre a importância do olhar na direção da saúde com a nova metodologia de aprendizagem ativa, e não alimentar a doença, como se vê hoje diante da desumanização na área médica. A consciência plena e docência, a vivência pessoal como instrumentos de qualificação das relações transpessoais e metadisciplinares de profissionais da saúde, seria a aprendizagem ativa atuando sobre o futuro médico.

Para estar no lugar de docente é necessário ser inspirador, firme, prático, coerente, pró-ativo, isto é, ter a aprendizagem ativa como uma filosofia de vida e não apenas uma técnica metodológica. Ter como desafio aumentar a motivação dos alunos usando ferramentas interativas, atividades significativas, trabalhos em grupo, situações reais da vida para construção do conhecimento de dentro pra fora, sendo o aluno proprietário do seu processo de aprendizagem. Para isso, serão incluídas atividades vivenciais e plenitude mental como base de todas as atividades indo na direção da construção da consciência corporal e emocional nos alunos implicados no processo de aprender, a fim de equilibrar intelecto e sabedoria.

Falamos de mudança que por sua vez vem acompanhada de transição. Mudança, segundo manuais e livros do curso internacional de qualidade educacional "Teach, Learn and Quality" é algo que acontece rapidamente, é situacional e acontece sem que as pessoas enfrentem transições. Transição é um processo cognitivo (co- + gnocere + -ition) equivale etimologicamente à ação de vir a conhecer (Biolchini/, 2012, p. 309) onde as pessoas precisam acolher novos conceitos e detalhes de uma nova abordagem, com as alterações que dai advém como, por exemplo, uma nova forma de aprender e ensinar, usando a aprendizagem ativa, com atividades cooperativas e de autoconhecimento. Enquanto a mudança refere-se à utilização de novas ferramentas, a transição refere-se às diferentes formas de ensino e atuação com diferentes formas de 
aprendizagem, uma verdadeira mudança de paradigmas, logo é difícil de lidar. As transições situam-se em diferentes eixos, aqui definidos como afirmações polarizadas e formas de aprendizagem, da tradicional à socioconstrutiva. Ficam assim apresentadas as direções ${ }^{1}$ :

\section{DE}

_ atividades úteis

_ foco no produto

_execução de tarefas

_ competências receptivas

_aluno passivo

- receber

_aprendizagem centrada

no sujeito

_ professor especialista

\section{PARA}

atividades significativas, foco no processo e procedimentos tomada de responsabilidade competências de raciocínio aluno como proprietário do seu próprio processo solicitar projetos baseados em tarefas, resolução de problemas

professor como treinador

Todo esse caminhar PARA, geram fases a serem vividas passo a passo, tais como as três fases abaixo que caracterizam o processo de transição:

1. Conclusão de uma forma de pensar e agir tradicional. Esta fase surge acompanhada por negação, choque, ira, frustração e estresse.

2. Entrada de uma zona neutra, onde a segurança do tradicional desaparece e as novas formas de agir ainda não são claras e transparentes. Surge com emoções de ambivalência, ceticismo, mas dando lugar à aceitação.

3. Estabelece-se a nova situação dando origem a uma nova corrente. Esta fase vem acompanhada de impaciência, esperança e entusiasmo.

\footnotetext{
${ }^{1} O$ projeto $T L+Q$ está focado em ações que afetam a gestão da escola e a prática em aula. In: http://www.tlqproject.eu/ Estas direções se encontram no Manual intitulado "Métodos de Ensino Motivadores e Criativos" e faz parte do projeto TL+Q (Teach, Learn and Quality). Disponível em: http://www.tlqproject.eu/por/pdf/MTLM\%20portuguese\%20TLQ.pdf
} 
Desde os primórdios da humanidade, o ser humano busca e segue modelos. Esse movimento se dá devido aos deslocamentos e conquista de espaço para sobreviver. $\mathrm{Na}$ sobrevivência, observam e experimentam novas relações com o ambiente cultural e com o outro e vão descobrindo-se e formando redes a cerca de si, do outro e do meio, gerando novos saberes e conhecimento científico que foram se instalando com autoridade e se tornando denominadores comuns da racionalidade e autodefesa, logo foram sendo deixados de lado os seres em formação, seja em escolas ou universidades, o sensível, o subjetivo, o essencial assim como a consciência de si, do outro e do meio, sendo banida do contexto.

$\mathrm{O}$ modo de ser e de estar no mundo está intimamente ligado à singularidade do humano, as peculiaridades e diversidades do Ser-Saber-Fazer inscritas em cada um de nós e que representam a possibilidade de nos diferenciarmos. Desde a mais tenra idade nos relacionamos com "os mundos" interno e externo a nós mesmos, seja pelo contato visceral gestacional, seja pelas várias modulações do toque, da voz, da respiração, do olhar, da escuta, de nossa própria presença no mundo que nos coloca permanentemente em ação-reação desde nossos corpos frente a tudo com o que entramos em contato (Lapierre \& Aucouturier, 1984).

Partindo desta importante base e à luz dos estudos de Lapierre, a disciplina clinica "Tristeza" no ciclo 2, será o elemento desencadeador para estimular novas relações humanas na Medicina no desenvolvimento do diagnóstico. Deste modo, diante da possibilidade de trazer para dentro do currículo de formação a nova metodologia, de poder ir além do estritamente pedagógico, elaborando uma Formação Pessoal, até chegar ao ser completo das suas competências, desconstruindo imagens congeladas e ampliando novo saberes e configurando a partir daí um futuro médico que terá condições para o diagnóstico de um sintoma como Tristeza, tão subjetivo, mas tão rico de memórias. O diálogo com a concepção de ontogênese do ser (Ajuriaguerra, 1972) assim como os estudos de Stephen Jay Gould (1977) sobre o Ser Humano inacabado será fundamental na construção teórica deste tema.

A implementação de novos modelos Pedagógicos introduz novas variáveis cujo impacto, designadamente em termos de saúde importa conhecer, tendo como 
objetivo analisar as associações entre modelos pedagógicos próximos aos tradicionais e variáveis psicológicas.

A consciência plena através da vivência pessoal como instrumento de qualificação das relações transpessoais e metadisciplinares utilizando a plenitude mental, perguntas, brainstorm, pesquisas extraclasse, casos, filmes, vídeos, fotos, mapa conceitual, trazer as ferramentas adequadas e encontrar as bases para o bom e correto uso das competências. Tornar competente é saber usar as competências certas durante o processo. Sensibilizar e integrar para em seguida estar apto a ouvir, ver além, perceber para diagnosticar.

Aguçar os sentidos (fonte que afeta o olhar do mundo), desenvolvendo foco de o que quero, como quero e como realizar o processo.

No primeiro capítulo deste trabalho, temos o Ciclo1 com a unidade intitulada “Atenção materno-infantil", que está apoiada sobre as bases para seguir a trilha de uma medicina humanizada, que leva em conta o todo e a saúde. A importância da sensibilidade e do autoconhecimento para a consciência plena na medicina, a realidade social integrada à individual na construção de um novo olhar com mudanças de paradigmas. O ciclo1 é a representação da construção desta base para todo o processo de crescimento pessoal e profissional do qual o aluno e futuro médico estará apoiado para realizar a verdadeira medicina.

O segundo capítulo refere-se ao Ciclo2, onde o tema tristeza terá a continuidade do processo iniciado no ciclo1, tendo como meta a percepção e escuta dos sintomas a fim de poder diagnosticar e fazer a terapêutica adequada. Assim, enquanto o ciclo1 sensibiliza, o ciclo2 diagnostica, gerando conhecimento, habilidade, e atitude, levando a alcançar a meta- competência. O caminho está na construção e deve ser feita em bases sólidas e não rígidas, pois a rigidez representa mais fragilidade e solidez mais sensibilidade.

É importante frisar que tanto no ciclo 1 quanto no ciclo 2 está presente o processo de transição para o novo paradigma, essencial para a formação dos futuros médicos e docentes. O mapa abaixo, que foi elaborado em grupo no Seminário 3, sintetiza esta transição: 
Figura 1: Mapa conceitual da relação professor aluno

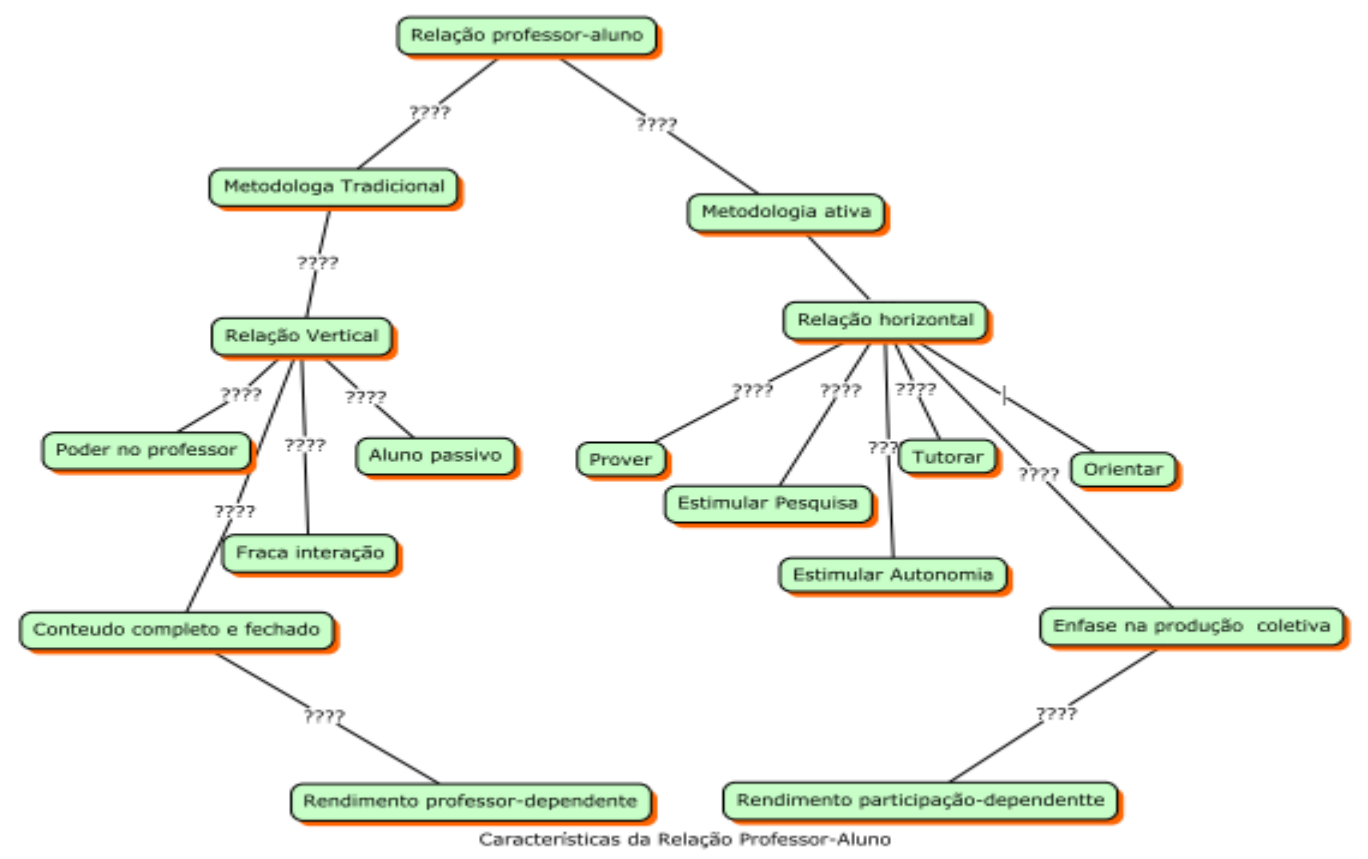

Agora é o inicio para a travessia - espero que o leitor não venha a considerar como uma interrupção, mas ligação, tendo varias finalidades: examinar noções às quais irei recorrer frequentemente (por exemplo: organismo, corpo, cérebro, comportamento, mente, estado); discutir rapidamente as bases neurais do conhecimento, realçando sua natureza parcelada e a dependência de imagens; e fazer alguns comentários sobre o desenvolvimento neural, cognição e emoção. 


\section{2-}

\section{Ciclo1: Atenção Materno-infantil.}

Suas crenças se tornam seus pensamentos.

Seus pensamentos se tornam suas palavras.

Suas palavras se tornam suas ações.

Suas ações se tornam seus hábitos.

Seus hábitos seus valores.

Seus valores o seu destino.

Mahatma Gandhi

A unidade pedagógica do ciclo1, consiste em um período de 15 semanas em 4 semestres (alunos de 18 à 21 anos), sendo esse tema como problema integrador, abordado no $4^{\circ}$ semestre segundo as diretrizes da MED PUC Rio.

Frans Veldman (2007) me fornece uma bela representação da área cognitiva a partir do afetivo-emotivo, onde se enquadraria toda a leitura na formação da criança em um Ser pleno para a autenticidade e segurança do futuro adulto. Relação maternoinfantil como uma ciência da afetividade.

O desafio neste ciclo é fazer da classe um laboratório motivado pela adoção de estratégias de aprendizagem eficazes, para formar alunos conscientes da importância de serem alunos ao longo da vida, dando início ao processo de construção do indivíduo no mundo do Ser, Saber, Fazer, sendo para si e para o mundo.

O uso de disparadores como filmes e vídeos, imagens com base na Plenitude Mental (mindfulness), são ferramentas utilizadas na sensibilização pessoal. Através de grupos formados aleatoriamente, sem escolhas e bem diversificados, para a busca das necessidades individuais e coletiva intra e extraclasse, priorizar as ações e planejamento no grupo, elaborar críticas e soluções organizando a atenção à saúde materna- infantil e constatar que esta fase é o começo de todo o desenvolvimento psicomotor e da vida adulta. É importante ressaltar que a saúde física e emocional é inseparável e caminham juntas. Memórias e pensamentos tem como base uma vida feliz e saudável. 
Durante o semestre, a unidade Materno-infantil é desenvolvida e pautada em um programa de quatro momentos, aqui descritos individualmente, mas que no cotidiano das aulas vão produzir uma rede de saberes e fazeres (Coelho, 2009). São eles:

\section{1- Vivência de Plenitude Mental - mediação cognitiva.}

Segundo Frans Veldman (2007), as faculdades de representações cognitivas tem suas relações mútuas, formando a tríade $\mathrm{A}, \mathrm{B}, \mathrm{e} \mathrm{A}+\mathrm{B}$. Na primeira tríade (A) o cognitivo é apenas racionalidade, intelectualidade e é de natureza interativa, onde só o que interessa é o útil. Na segunda tríade (B), o cognitivo é afetivo e manifesta-se a partir da interação do Emotivo-Afetivo, determinando a segurança de base e o sentimento de completude, a partir da natureza verdadeira e autenticidade humana. Quando a Relação Interativa entre as faculdades Cognitivas Afetivas se tornam incompletas, o senso de eficácia das faculdades Cognitivas Racionais é altamente perturbado e o equilíbrio entre as duas Tríades se rompe. Mas, se a Tríade Cognitiva Afetiva é bem elaborada e desenvolvida, a eficácia da Tríade Racional será "otimizada".

Figura 2 - INTERAÇÃO do A+ B

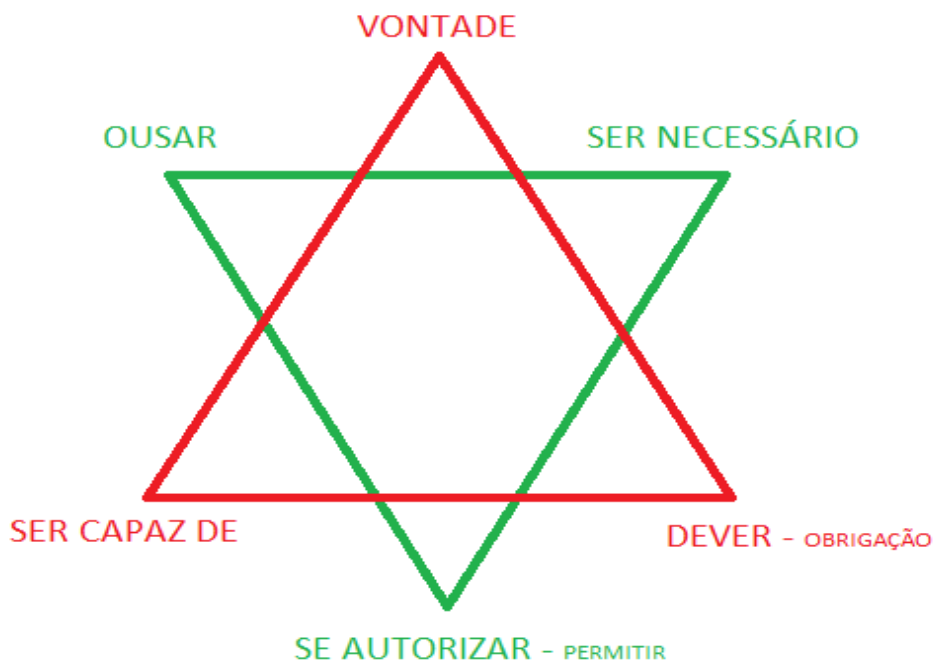


Em um olhar amplo, as vivências através dos sentidos (sentir, ver, ouvir) terão um lugar relevante na projeção do Ser-Estar no mundo, seguido de um espaço, ao final, para a livre manifestação das percepções e sentimentos no desencadear das atividades nas relações internas e externas ao corpo, próprio e coletivo, favorecendo as bases das competências: A atitude, o conhecimento e a habilidade, a fim de que possa ter a competência comunicadora no foco, durante o processo, primeiro comunicar consigo mesmo para depois poder comunicar com o outro. Essa competência não é uma via única, mas uma via dupla. Comunicar significa ouvir na mesma medida e ser ouvido, significa saber ouvir. Todos os sentidos fazem parte da comunicação, não só a fala e a escrita comunicam, mas o olhar, o ouvir, o toque, o olfato, o paladar, sendo na minha concepção, essa competência, uma fonte primordial para o docente e discente, na arte de ensinar, aprender e de atuar na vida, profissional e pessoal.

Esse momento define, primeiramente, a expressão sensível ao movimento enquanto lugar de projeção do Ser-estar no mundo, seguido de um espaço, ao final, para a livre manifestação das percepções e sentimentos à que a atividade vai desencadear, o lúdico como laboratório e a escolha pessoal como experiência. Nessas bases me identifico com Coelho (2009) que propõe

(...) elementos desencadeadores de relações internas e externas ao corpo, próprio e coletivo, mediadas por situações lúdicas que convidem os alunos a deslocarem seus corpos no espaço-tempo de uma sala de aula portadora de uma nova e flexível configuração já que mesas e cadeiras assumiriam outras funções e significados durante as vivências (p.872).

O tema propriamente dito, relação materno-infantil, tem como base teórica a ontogênese (transformações embrionárias e pós-embrionárias do ovo até a forma adulta e que se prolonga por toda vida do indivíduo) e o princípio do Ser inacabado (neotenia, segundo Gould, Stephen Jay, 1977), ao qual cada experiência é o laboratório das suas próprias histórias e o encontro com as histórias dos outros, traz informações sobre o ser genético, específico e individual; fenótipo (características morfológicas, fisiológicas ou comportamentais observáveis no individuo) e genótipo (qualquer dos aspectos hereditários que exercem uma influencia causal no desenvolvimento individuo); variabilidade, integração com o meio no processo de adaptação e complexidade do Ser Humano e o seu inacabamento biológico. 
Esse contexto serve de estrutura para a leitura do caminho individual e genético a partir da própria família e do comportamento adquirido diante da sobrevivência e da história pessoal. Mostra que é possível alterar comportamentos e crenças e passar de mera "vítima" para "co-criador". Ter como uma só resposta "quero ser eu mesmo", "posso ser eu mesmo" e "estou sendo eu mesmo".

Esse processo remete ao mesmo desenvolvimento das sensações da idade infantil e maternal, com todas as suas heranças genéticas comportamentais, tendo a própria experiência como material de um olhar para dentro e para além de si e desenvolve uma maior capacidade de encontrar os processos sociais e culturais na posição de futuro médico com uma análise crítica diferencial estando mais perto do saber- fazer com o domínio do conhecimento a partir de si, com habilidade e atitude.

Durante o processo, o aluno deve anotar cada repercussão e descoberta da sua imagem comportamental (plenitude mental) e genética (pesquisa familiar), dificuldades e relevância dos conteúdos aprendidos e vividos, tendo como finalidade ter material didático para a próxima etapa que será a de reflexão do vivido e elaboração das possibilidades, não só pessoais, mas sociais dos quais estiveram em contato. Encontrar as condições de acolhimento ao tradicional (sua zona de conforto), novas formas de pensar, olhar e agir. Algumas perguntas servirão para desencadear esse processo:

A) Porque razão o ser humano, na sua semelhança como ser, ao mesmo tempo apresenta diferenças?

B) Como é transmitida essa diferença comportamental de uma geração a outra? O que influencia e onde se coloca na sua história de vida?

C) Até onde os sentidos alteram o olhar do mundo?

D) Qual a importância na vida infantil na relação com a mãe, pai e o ambiente social e cultural?

E) Como isso teria peso na vida adulta (emocional, social e profissional)?

F) Você já se situou em alguma observação e autoanálise?

Baseado nas respostas e debates sobre as experiências vividas, entramos na segunda etapa do desenvolvimento no processo de sensibilização e aprendizagem, que é de desenvolver a reflexão sobre o vivido. 


\section{2- Reflexões sobre o vivido - Caminhar para Si}

Esse segundo momento é o lugar para reflexões sobre o vivido na etapa anterior e traz para o centro do diálogo as relações diretas e / indiretas com a vida, observa os aspectos individual, relacional, formativo e profissional. Nesta etapa resultam algumas sínteses expressivas em que foram registradas as percepções individuais e coletivas que a reflexão sobre o vivido desencadeou no contexto da formação acadêmica e dos currículos de formação. Este momento, baseada em Coelho (2009), nomeio de Reflexão sobre o vivido-caminhar para si.

O tema do Caminhar para si é objeto de estudo de Josso (2004), sobre experiências de vida e formação e Coelho (2009) de forma muito interessante aproxima ao processo de reflexão sobre o vivido na medida em que também

se trata, de fato, da atividade de um sujeito que empreende uma viagem ao longo da qual ela vai explorar o viajante, começando por constitui o itinerário e os diferentes cruzamentos com caminhos de outrem, as paragens mais ou menos longas no decurso do caminho, os encontros, os acontecimentos, as explorações e as atividades que permitem ao viajante não apenas localizar-se no espaço-tempo do aqui e agora, mas ainda, compreender o que o orientou, fazer o inventário da sua bagagem, recordar os seus sonhos, contar as cicatrizes dos incidentes de percurso, descrever as suas atitudes interiores e os seus comportamentos. Em outras palavras, ir ao encontro de si visa a descoberta e a compreensão de que viagem e viajante são apenas um (Josso, 2004, apud Coelho, 2009, p.873).

Nesta etapa vamos dando a sequência na direção da transição que, por sua vez, começará a entrar em uma zona neutra sem formas claras e a ambivalência dando lugar ao ceticismo indo na direção da aceitação. A abordagem das complexas conexões existentes entre o comportamento humano, a psique e as primeiras experiências marcantes da pessoa diferenciando causa e efeito. Com o uso de problemas (PBL) e/ou casos, será possível um trabalho da reflexão sobre a leitura da causa/efeito diante da leitura do problema encontrado nas bases materno-infantil com a finalidade de desvendar possíveis causas que estão relacionadas. 
Estas ferramentas trazem o desenvolvimento de investigação e foco o que é de grande importância em diagnósticos, pois terá importância nas considerações das causas possíveis, mesmo que o grupo ache que uma causa específica não seja responsável. Uma delas é o diagrama de Causa e Efeito também conhecido como Diagrama de Ishikawa, ou Espinha de Peixe. O nome Ishikawa tem origem no seu criador, Kaoru Ishikawa que desenvolveu a ferramenta através de uma idéia básica: Fazer as pessoas pensarem sobre causas e razões possíveis que fazem com que um problema ocorra.

Costuma ser aplicado em grupos interdisciplinares, de forma que o grupo tenha condição de detectar e que cada participante contribua com seu conhecimento específico.

\section{Figura 3- Diagrama Espinha de Peixe:}

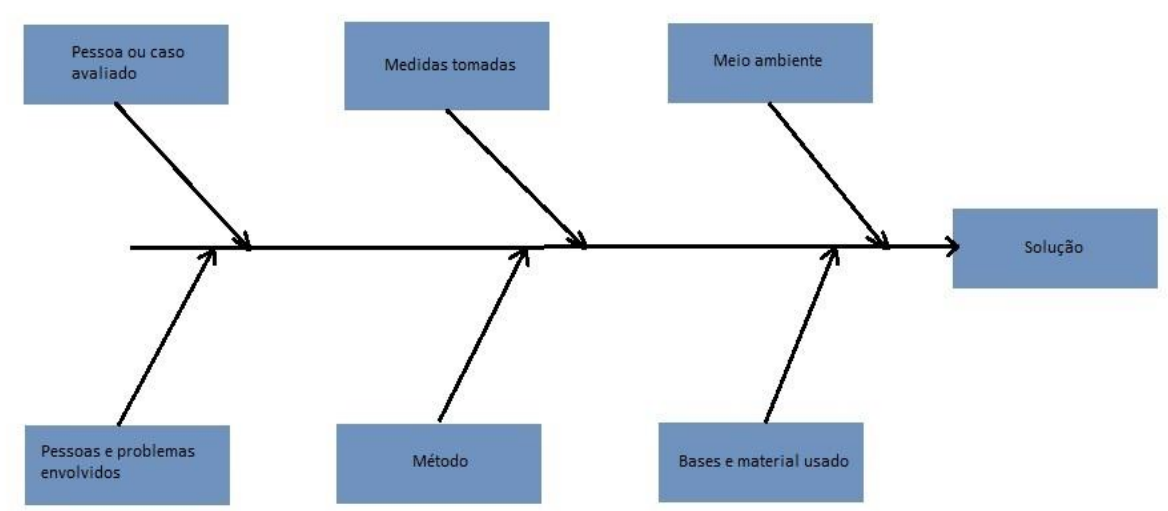

Desenvolvendo esse conteúdo e desvendando possíveis causas, sempre tendo como base a sua leitura pessoal, fazendo relações a fim de que adquira consciência de que tudo o que faz parte de nós, interfere no encontro com o outro e que não existe este lugar de ficar totalmente neutro porque somos passíveis todo o tempo de entrar no mundo do outro nos misturando e espelhando reações que tiram o foco e a visão do real. Esta crença da total neutralidade está por trás de uma medicina que se protege tanto que não se relaciona. É necessário questionar este paradigma no começo da formação acadêmica, porque só assim teremos médicos humanos que podem sentir sem ter que se proteger, e isto só são possíveis estando diariamente em contato com o seu caminhar para si. 
Todo o conteúdo trabalhado encontra uma análise teórico-metodológico que faz parte da terceira etapa da disciplina. Neste ponto já se fazem mais claros os objetivos e os conceitos que a disciplina propõe desenvolver, facilitando a compreensão e a transposição do teórico para a ação pedagógica bem como a compreensão acerca da relação consciência e saúde.

\section{3- Leitura e análise teórica - metodológica: estudo do conteúdo}

Os métodos empregados agora estão sendo analisados na implicação de sua utilização, limitação, potencialidade e distorções para a abordagem do que foi mais ou menos importante nos processos anteriores.

As bases de início são através de perguntas a fim de se situar diante do processo individual para depois encontrar e trocar com o outro em grupos de estudo com base nas três competências (CHA), que serve de patamar para as outras competências como a técnica, a ética (um conjunto de valores e princípios que usamos para decidir: Quero? Devo? Posso?) e a comunicadora (tipo, forma de linguagem atenção paciente/família e clareza na informação). Estando reunida toda a pesquisa pessoal e social sobre o tema materno-infantil, pode-se partir para a ação de encontrar soluções e utilizar em grupo os métodos convenientes para construção de todo o percurso pedagógico. Analisar qual competência é mais presente e a importância desta tomada de consciência. Se situar na sua própria dificuldade, e vir, a saber, a do grupo.

Esses novos modelos pedagógicos, com suas novas variáveis, são discutidos sobre o impacto designado na Saúde. Tomar as medidas de stress, regulação emocional e manifestações físicas na direção de um caminho para futuros diagnósticos.

Poder avaliar as dimensões de desregulação emocional dos quais se encontram listadas, sempre em paralelo com as competências possíveis e necessárias ao processo. Listar as queixas habituais e stress por situações recentes. Foco nos objetivos a alcançar, integrando-os. Enumerar os valores para em seguida partir para perguntas baseadas em: Que ações fazer, quem usaria mais efetivamente os recursos, que recursos facilitariam e quais os mais importantes critérios para avaliação, questões estruturadas em triadas conceituais das competências, conhecimento, habilidade e atitude, no assoalho das ações de planejamento local, na organização do acesso à saúde pública e quais medidas seriam necessárias na prevenção das epidemias clínicas, seguido de reflexão na direção da meta- competência. 
Segundo Rui Gabriel ${ }^{2}$, as manifestações do conhecimento têm como referências as tomadas de consciência: 1-inicial: não sei que não sei; 2-Desenvolvido: sei que não sei e sei do valor de saber; 4-Ser proficiente (o saber fazer parte da natureza pessoal) para que sempre possamos recomeçar o processo em uma nova direção, ir além de ser só competente (meta-competência).

Por fim, na qualidade de processos, dos três momentos acima descritos, destaco um quarto momento que foi sendo tecido pela dinâmica de cada encontro e todos ao mesmo tempo, que resulto no que identifiquei como Produção de Sentido, representando o percurso do caminhar para si ao revelar-se ao outro.

\section{4- Produção de sentido- do caminhar para si ao revelar-se ao outro}

Inspirada em Coelho (2009), proponho que a disciplina nesta etapa reconstrua o processo, os saberes e o lugar da tomada de consciência sobre si, sobre os outros e sobre o meio na relação educativa. A autora a partir de um protocolo de observações levanta questões:

1- Como lidaram com o desafio de disponibilizarem-se corporalmente para as vivências de Plenitude mental?

2- Que reações foram nomeadas como importantes?

3- Como se sentiram após as vivências e de se permitir expressá-las?

4- Nos dias que se seguiam, quais as percepções e/ou repercussões?

5- Que aprendizagem esta etapa da disciplina proporciona e agrega no processo formativo e coletivo?

6- Que valor a experiência em Plenitude Mental agrega para a vida profissional?

7-De que modo às vivências de Plenitude Mental e a reflexão sobre o vivido contribuíram para o método de aprendizagem ativa dos conteúdos da disciplina?

$\mathrm{Na}$ elaboração das respostas ora individual, ora coletivas, serão revelados saberes que estavam para além daquele espaço-tempo disciplinar transitando pela

\footnotetext{
${ }^{2}$ Os 4 níveis de competência. In: http://www.blogderuigabriel.com/treino-os-4-niveis-decompetencia/
} 
filosofia, pela lógica, pela retórica, pela arte, pela cultura, pela psicologia, pela espiritualidade, pelas demais disciplinas que compõe o currículo do semestre, do curso como um todo, mostrando como deve ser o exercício da medicina. Desta forma, o objeto dos estudos acordados pela disciplina, promoverá uma resposta metadisciplinar a um projeto transdiciplinar, pautado pela não fragmentação dos saberes.

É importante frisar que o aprendizado existe de ambos os lados no momento em que a nova metodologia se faz presente, não ter medo de errar e de mudar, independente de ser aluno ou professor. Sobre isso, Cortella (2014) nos diz:

A principal característica da humildade pedagógica é a noção de que alguém sabe coisas, mas não as sabe todas, e que outro as sabe. Sabe outras, mas não sabe tudo, só a possibilidade de estruturar uma conexão entre pessoas pode gerar, de fato, um conhecimento que seja coletivamente significativo. A humildade pedagógica é, portanto, a qualidade essencial de alguém que se disponha a educar, porque só quem é permeável a ser educado pode também educar (p.40).

\subsection{Avaliação}

A avaliação faz parte de um processo continuo que envolve esperança, lucidez e ação. Segundo Luckesi (2000, apud Tuttman 2013, p.103),

Avaliar um educando implica, antes de qualquer coisa, acolhê-lo no seu ser e no seu modo de ser, como está, para, a partir daí, decidir o que fazer. A disposição de acolher está no sujeito do avaliador, e não no objeto da avaliação. O avaliador é o adulto da avaliação, por isso ele deve ter a disposição de acolher. Ele é o detentor dessa disposição. E, sem ela, não há avaliação. Não é possível avaliar uma pessoa ou uma ação, caso ela seja recusada ou excluída, desde o inicio, ou mesmo julgada previamente. Que mais se pode fazer com uma ação ou pessoa que já foram recusados desde o primeiro momento? Nada, com certeza!

Esta concepção de avaliação me autoriza a repensar o já instituído e pensar o novo, ter certezas e dúvidas, apresentar ideias, ouvir críticas e avançar no entendimento do ato de avaliar que efetivamente contribua para a prática educativa. 
De acordo com Lukesi e Josso, os olhares caminham na mesma direção do conhecimento e das bases necessárias na origem ao paradigma sistêmico, de modo a dar conta dos intercâmbios de matéria, energia e informação, e suas múltiplas interações, as quais ocorrem em diferentes níveis organizacionais dos seres vivos. Neste sentido, texto e contexto tornam-se dimensões de um mesmo fenômeno, e não separados de existência.

É dessa forma que entendo o processo cognitivo e nele o ato de avaliar. A avaliação engloba auto-avaliação, avaliação individual no grupo e avaliação do professor.

No término do semestre da disciplina (materno-infantil) estudada, o aluno deve saber avaliar os processos ocorridos, bem como os resultados obtidos através do conhecimento do mundo interno percebido. Durante todo o semestre e semanalmente serão feitas avaliações de forma continua e diagnóstica, comparando o antes e depois, indo na direção da Meta-Aprendizagem, sendo uma avaliação inclusiva que indica o que ainda se pode vir a saber.

Os objetivos estão em saber a linha de raciocínio estimulada no cognitivo (afetivo, memória, estimulo, criatividade, atenção), no pedagógico (debates, discussão) e tecnológico (a organização das ideias e acesso a artigos e imagens).

Neste contexto estariam presentes temporalidade, conhecimento, atenção, cuidados, unidade, comunicação, ética, saber ouvir, observar, já que a ferramenta principal foi trabalhada no ciclo: A consciência de Si em relação ao outro.

Uma proposta de avaliação deste ciclo1 é a construção de uma narrativa individual de um caso no qual esteve envolvido nas pesquisas extraclasse, relacionado com processos pessoais, na condição de uma nova leitura e solução a partir da própria história materno-infantil, sendo necessário encontrar o ponto convergente, onde suas emoções estiveram presentes, relatando como se auto - avaliou na prática e o grau de inteireza no contato com o outro. Essa apresentação será livre na escolha dos métodos. Portanto para que a realidade seja bem percebida, é imprescindível saber coletar dados relevantes e definir que informações se fazem necessárias para evidenciar as potencialidades e dificuldades apresentadas pelos alunos, bem como os instrumentos mais adequados para a captação e a forma de aplicá-los e apresentá-los, já que foram utilizados durante todo o processo da unidade na metodologia de aprendizagem ativa, na 
construção do primeiro pilar da sustentação da ponte da nossa travessia, agora no capitulo seguinte, ciclo2.

\section{3.}

\section{Tristeza- saúde mental e transtornos afetivos: Ciclo 2}

O processo a que chamamos "VIDA" pesa em todas as suas dimensões de presença sobre cada um de nossos instantes e ao mesmo tempo parece fugir de todas as tentativas que fazemos para captá-lo. Jean Paul Resseguier

Segundo Godoy (2011), Spinoza nos fala de dois afetos, ou paixões primárias da alma, que são: a alegria e a tristeza. A alegria é o afeto que aumenta nossa potencia de agir, uma variação intensiva positiva, para mais. Já a tristeza é o afeto que faz com que aconteça uma diminuição da nossa potencia de agir. Podemos dizer então que a alegria está ligada à expansão, e a tristeza à contração. A nossa resposta a esses afetos é que vai diferenciar se estamos agindo passivamente, apenas reagindo aquilo que nos afetou, ou ativamente, levando-nos a reflexão. Isso é o que Spinoza chamaria de um bom encontro.

Usando a base desse encontro de Spinoza, estamos agora construindo a travessia na direção da unidade pedagógica do ciclo2.

Após o trabalho realizado no ciclo1, onde os alunos trilharam um percurso em direção a si mesmo, e aprenderam a importância de uma escuta atenta. No ciclo seguinte regressarão à historia principal e tratarão da regulação biológica e de sua expressão nas emoções e nos sentimentos. O objetivo deste ciclo (Tristeza) é chegar ao diagnóstico pela aprendizagem ativa.

Para esta tarefa precisa estar desenvolvido o raciocínio indutivo e dedutivo, pensamento sistêmico, construção e comunicação de explicações, argumentos baseados em dados, interpretação de fenômenos e previsibilidade de mudanças, selecionando conclusões a partir das evidências. Processo e planejamento são à base da construção do foco nesta dinâmica de trabalho.

Neste momento é importante indagar quais serão os meios necessários para alcançar o objetivo. Com que? Ferramentas metodológicas para atingir o objetivo. Para 
que? Ser capaz de diagnosticar e dar soluções. Essa dinâmica ajuda a priorizar, sendo muito importante para que haja amplitude e aprofundamento para o melhor desfecho do objetivo. Trabalhar para aprofundar, ampliar, definir e se orientar. Escolher ferramentas metodológicas, como brainstorm e tecnologia no intuito de ver o produto cognitivo, pedagógico e tecnológico para o estimulo do raciocínio.

Vamos definir o conteúdo deste capitulo como uma misteriosa aliança (Damasio, 1996, p.109) que une o capitulo anterior na elaboração das explicações e fechamento de uma etapa iniciada. Vamos à direção de uma investigação, que conduz a identificação de um conjunto de processos neuropsicológicos. Assim, a meu ver, o fato de se ter uma mente significa que ela forma representações neurais que se podem tornar imagens manipuláveis num processo chamado pensamento, o qual acaba por influenciar o comportamento.

- A dinâmica é focar e ser preciso nas prioridades, a fim de dar início através de disparadores como facilitadores (plenitude mental, vídeos, filmes, problemas, casos). Redefinir valores e forma e ressignificá-los em três momentos, por conseguinte:

No primeiro momento, os alunos retornam e se preparam para fazer o resgate do conhecimento adquirido para o uso das estratégias de raciocínio. No segundo momento, o resgate do processo da emoção e dos sentimentos para a integrante maquina cerebral e na regulação biológica, cujo cerne é constituído por controles homeostáticos, impulsos e instintos. No terceiro, o resgate do design do cérebro e todos os seus sistemas localizados, tendo em seguida o encontro com a misteriosa aliança dos processos postos a descoberta no fim do ciclo anterior. Poderão ser colocadas em pratica as decisões pessoais e sociais que estão repletas de incertezas e que tem impacto na sobrevivência, direta ou indiretamente, constatando, que qualquer escolha ou decisão, será sempre diferenciada para cada caso ou problema encontrado, e raramente igual.

Na relação materno-infantil (ciclo1), trabalhamos a importância da proteção e da segurança como conhecimento adquirido. Nesse estudo os diversos mecanismos de sobrevivência que estamos sempre usando como proteção e segurança foram observados pessoal e socialmente em situações reais.

Ao longo do processo de crescimento, a proteção é controlada pelo sistema nervoso, responsável por monitorar e interpretar os sinais do ambiente e estimular reações apropriadas. Ele age como líder e sempre quando surge uma situação de 
ameaça, sua função é alertar a comunidade celular. As células geralmente respondem a uma variedade básica de "percepções" do que se passa no mundo. Essas percepções incluem níveis de potássio, cálcio, oxigênio, glicose, toxinas, luz e diversos outros estímulos no ambiente.

O cérebro e o corpo encontram-se indissociavelmente integrados por circuitos bioquímicos e neurais recíprocos dirigidos um para o outro e indo mais além, essa relação cérebro - corpo geram respostas espontâneas e reativas que são conhecidas como comportamento. As influências genéticas no comportamento, são as especificas e as individuais.

Específicas: parte dos genes que é própria de uma determinada espécie e é comum aos vários indivíduos e distingue as espécies de outras espécies- genótipo (a mutação altera o genótipo).

Individuais: parte dos genes que é responsável pelas características únicas, própria de cada individuo e que distingue uns dos outros da mesma espécie. A hereditariedade especifica torna-nos humanos e a hereditariedade individual torna-nos únicos - fenótipos (não afeta o código genético).

Terceiro resgate, as emoções, os sentimentos, e então mergulhamos no Tema da unidade propriamente dito, a Tristeza. Nesse estudo estão incluso os transtornos afetivos, tais como: depressão, bipolaridade, angústia, ansiedade, medo, todos eles rondam esse tema que é a representação da ação do ambiente sobre o organismo. O ambiente deixa marca de diversas maneiras, através dos olhos, ouvidos, pele, paladar e olfato. Essas representações integradas pelo cérebro resultam em movimentos atuando no ambiente que por sua vez haviam estimulado o movimento.

Segundo Wilhelm Reich (1978, apud Castel, 1995) a emoção é um movimento protoplasmático expressivo. Biologicamente os estímulos prazerosos provocam uma "emoção" do protoplasma (é um sistema físico-químico de natureza coloidal que pode passar do estado sólido ao líquido na célula, capaz de sentir e reagir a estímulos) do centro para a periferia da célula, e os estímulos desagradáveis provocam "remoção", da periferia para o centro. Estas duas direções básicas da corrente biofísica plasmática correspondem aos dois afetos básicos do aparato psíquico, prazer e angústia.

Essa função protoplasmática nos lembra de Spinoza para quem a alegria está ligada à expansão e a tristeza à contração. Essas duas vertentes filosóficas se ligam atravessando o tempo e permanecendo vivas. 
A essência da tristeza e da alegria é a percepção combinada de determinados estados corporais e de pensamentos, ambos são acionados pelo mesmo sistema, mas quando estados corporais e pensamentos negativos se repetem com frequência e persistem, resultam na depressão e na deficiência do raciocínio e na alteração química.

\section{1- PROCESSO, PLANEJAMENTO e AVALIAÇÃo.}

A partir de todo o processo de resgate de conhecimento, temos a base para desenvolver a unidade durante o semestre. Tomei como base escolher um instrumento de trabalho ao longo deste ciclo, o ensino pela problematização: Aprendizagem Baseada em Problemas- ABP/PBL que vem sendo reconhecida como ativadora da integração ensino e serviço de saúde.

O ensino pela problematização ou ensino baseado na investigação (Inquiry Based Learning) teve inicio em 1980, na universidade do Havaí. É a proposta metodológica que define a maneira como os estudantes aprendem e quais habilidades cognitivas e afetivas são adquiridas. Fundamentou-se na pedagogia libertadora de Paulo Freire e nos princípios do materialismo e construtivismo de Piaget.

Essa concepção pedagógica baseia-se no aumento da capacidade do discente em participar como agente de transformação social, durante o processo de detecção de problemas reais e de busca por soluções originais. Marcada pela dimensão política da educação e da sociedade, o ensino pela problematização procura mobilizar o potencial social, político e ético do estudante, para que este atue como cidadão e profissional em formação (Mitre et al,2008, p.2139)

PROCESSO: A turma é dividida em três grupos. Cada grupo fica de posse de uma problematização a ser trabalhada. Durante as aulas terão a possibilidade de levantarem questões, críticas e discussões e ter como finalidade a melhor análise do PBL sendo desenvolvido. Fica ao encargo do grupo estipular ações e organização nas pesquisas e a quem nomear para o uso das competências que ali demandam, dando ênfase na técnica e comunicadora. Durante as aulas, as dúvidas e questões levantadas servem de parâmetro para ambos os grupos, sendo que podem utilizar da demanda do outro como fonte de trabalho, conhecimento e ética. Ter as aulas como fonte de compartilhar dúvidas, discussões e elaboração e não de competição. 


\section{Etapas para Diagnóstico:}

PLANEJAMENTO: O desenvolvimento e foco estão em construir a rota da trilha a ser percorrida. Mitre et AL (2008) citam o diagrama denominado Método do Arco o qual é constituído pelos seguintes movimentos: observação da realidade, pontos chaves, teorização, hipóteses de solução e aplicação à realidade. É o que mostra o diagrama abaixo

Figura 4- Método do arco

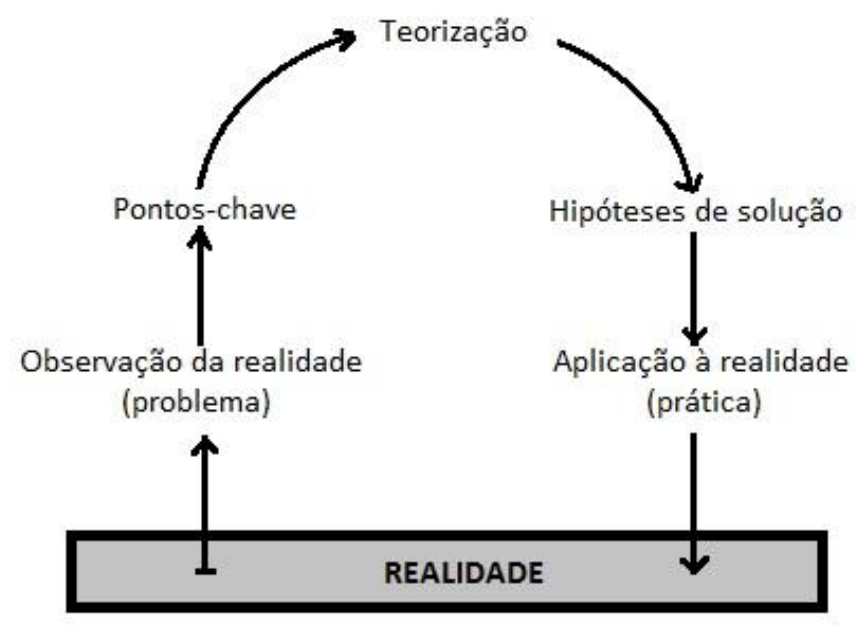

A primeira etapa é a da observação da realidade. $O$ processo está relacionado com um determinado aspecto da realidade que o grupo observa atentamente (cada aluno pode se interessar por aspectos diferentes dentro do seu grupo). Nessa observação, ele expressa suas percepções pessoais, efetuando a primeira leitura da realidade (conhecimento). Percepção, sensações e atenção, são instrumentos fundamentais nesta etapa.

$\mathrm{Na}$ segunda etapa, pontos chave, o grupo realiza um estudo mais cuidadoso e, por meio de uma analise reflexiva, seleciona o que é relevante, elaborando os pontos essenciais que devem ser usados para a compreensão do problema. Associações e projeções, campo dos fenômenos, farão parte. Perguntas (anamnese, entrevistas com a família buscando conhecer a historia do paciente) e as respostas com o informe psíquico do paciente e a família. 
$\mathrm{Na}$ terceira etapa, o aluno passa à teorização do problema ou à investigação propriamente dita. Todas as informações pesquisadas precisam ser analisadas e avaliadas para a resolução do problema. Nesse momento, o meu papel de docente será um importante estímulo para uma participação ativa dos alunos. Sendo essa teorização adequada, o grupo atinge uma melhor compreensão do problema na prática e teoria que irá sustentá-los.

$\mathrm{Na}$ confrontação da teoria com a realidade, o grupo irá, naturalmente, na direção da quarta etapa: a formulação de hipóteses de solução para o que foi estudado. Deve verificar se as hipóteses são aplicáveis à realidade, e o grupo pode ajudar nessa confrontação. É o momento da originalidade e criatividade, hora de inovar (habilidade). Avaliar o grau de instabilidade emocional, identificar a origem da instabilidade, elaborar diagnóstico diferencial e identificar o quadro de tristeza.

Chegamos à última fase, a aplicação à realidade. $\mathrm{O}$ grupo executa soluções encontradas como sendo mais viáveis e generaliza o aprendido para utilizar em diferentes situações. Poderá descriminar as possibilidades exercitando as tomadas de decisões e destreza (atitude). Planejar para aplicar a terapêutica.

Ao completar as fases o grupo pode exercitar a dialética de ação-reflexão-ação, tendo sempre como ponto de partida a realidade social e a importância do saber ouvir, saber expressar objetivamente, cuidar do tipo de linguagem diferenciada, se fazer ouvir, entender e observar, a fim de que se faça presente a competência comunicadora e ética.

Essa ação será concluída no final do semestre e apresentada em seminário, tendo em pauta a apresentação de todo processo de desenvolvimento, individual e em grupo. Relatar as dificuldades e facilidades, confrontos teóricos e emocionais, tendo em vista que, será o instrumento de avaliação do semestre na disciplina. A avaliação será individual entre os integrantes do grupo e também uma auto - avaliação (o que posso fazer melhor? meta-aprendizagem). Finalizando o processo de avaliação, será pedida aos alunos a elaboração de um mapa conceitual seguindo as diretrizes da figura abaixo. 
Figura 5- Mapa conceitual do tema: Tristeza

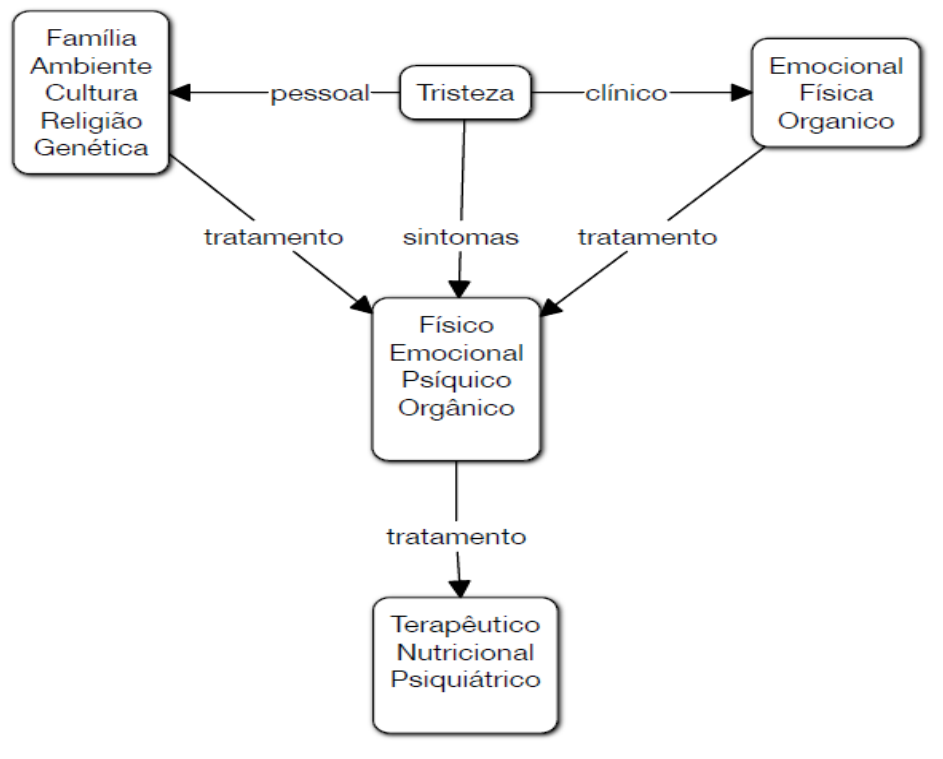

O professor receberá uma avaliação de cada aluno na forma escrita ou falada, individualmente, em dias agendados. Complementando o término da disciplina, o aluno trará seu portfólio com todos os momentos de prática, insights, consciência corporal e profissional, ou seja, as experiências vividas ao longo do semestre. Quantas e quais foram as dificuldades de romper bloqueios e como ajudou, ou não, ao processo de atuação em grupo e individualmente e como levou essa prática e resultados para o mundo. 


\title{
Considerações finais
}

\author{
O segredo da felicidade é a liberdade \\ O segredo da liberdade é a coragem
}

Tucídides - historiador grego

É importante dizer que as reflexões aqui expostas não podem ser consideradas inovadoras. O inovador, o novo, no entanto, é colocar as premissas defendidas em prática. Este é o nosso grande desafio. Este é o meu, o nosso compromisso de assumir, com toda a inteireza e paixão, o nosso papel de cidadãos no mundo.

É uma tarefa de troca entre as pessoas e, portanto, não o resultado de um depósito de conhecimentos, de um "iluminado e um obscuro e, tampouco, o descaso silencioso e injustificado do faz de conta no ensino" (Mitre et al,2008).

Segundo Mitre et AL (2008)

Uma educação voltada para as relações sociais emergentes desencadeia uma visão do todo, de rede, de transdisciplinaridade e de interdependência, as quais devem ser levadas a sério em um contexto de emergências dos novos referenciais da complexidade, do pensamento sistêmico e da ecologia profunda, genuína aproximação entre Ocidente e Oriente - e possibilitar a formação de um discente autônomo, capaz de construir uma aprendizagem significativa na ação-reflexão-ação.

A formação discente que este trabalho monográfico defende baseia-se, portanto, em práticas pedagógicas democráticas onde as jornadas individual e coletiva se entrelaçam e os valores do cuidado, da solidariedade e da fraternidade são construídos. No bojo desta concepção de formação de profissionais de saúde e medicina, situa-se um compromisso com a humanização do homem, onde o diálogo, a escuta de si e do outro, a humildade e o respeito pela potência de cada um, possibilitam uma verdadeira transformação. 


\section{5,Referências Bibliográficas:}

AGUIAR, AC.; RIBEIRO, E.C.O. Conceito e avaliação de habilidades e competência na educação médica: percepções atuais dos especialistas. In: Revista Brasileira de Educação Médica, Rio de Janeiro, v.34, n3, 2010.

ARANHA, R.N. et al. Proposta para uma graduação médica contemporânea : modelo MedPUC / ilustradora : Mary Paz Guillén. - Rio de Janeiro : Koan, 2011.

BIOLCHINI, Jorge. Tecnologias da Informação e comunicação na cognição situada. In: Tecnologias de comunicação e cognição / organizado por Fátima Regis, Anderson Ortiz, Luiz Carlos Aff onso e Raquel Timponi - Porto Alegre: Sulina, 2012.

CAPRA, Fritjof. A Teia da Vida: uma nova compreensão científica dos sistemas vivos. São Paulo: Cultrix, 2006.

CASTEL, Pedro. A massagem reichiana (intervenções mecânicas ou emocionais).1995.Disponível em: http://www.ifp-reich.com.br/site/wpcontent/uploads/2013/05/A_massagem_reichiana.pdf

COELHO, Maximila Tavares de Quadro. Consciência corporal e docência: a vivência psicomotora como instrumento de qualificação das relações transpessoais e metadisciplinares de profissionais da educação infantil e anos iniciais do ensino fundamental. Actas do $X$ Congresso Internacional Galego-Português de Psicopedagogia. Braga: Universidade do Minho, 2009. Disponível em: http://www.educacion.udc.es/grupos/gipdae/documentos/congreso/xcongreso/p dfs/t3/t3c59.pdf.

CORTELLA, Mario Sergio. Educação, Escola e Docência: novos tempos e novas atitudes. São Paulo: Cortez, 2014.

DAMASIO, Antonio. O erro de Descartes: emoção, razão e o cérebro humano. São Paulo: Companhia das Letras, 1996.

GODOY, Paula. O corpo, a potência e os afetos segundo Spinoza. Caderno de Filosofia. 2011. Disponível em:

http://www.existencialismo.org.br/jornalexistencial/paulaspiniza.htm

LAPIERRE, A. \& AUCOUTURIER, B. Fantasmas Corporais e Prática Psicomotora.Editora Manole: São Paulo, 1984.

MITRE, Sandra Minardi et al. Metodologias ativas de ensino-prendizagem na formação profissional em saúde: debates atuais. Ciênc. saúde coletiva [online]. 2008, vol.13, suppl.2, pp. 2133-2144. ISSN 1413-8123. Disponível em: http://www.scielosp.org/pdf/csc/v13s2/v13s2a18.pdf

TUTTMAN, Malvina Tania. O verdadeiro compromisso. Revista Retratos da Escola. Brasília, v. 7, n. 12, 2013. Disponível em: http://www.esforce.org.br/index.php/semestral/article/view/264 
VELDMAN, Frans. Haptonomie Science de l'Affectivité : Redécouvrir l'Humain. PUF, Paris, 2007. 